International Journal of Biological Sciences

ISSN 1449-2288 www.biolsci.org 2008 4(2):111-115

Research Paper

CIvyspring International Publisher. All rights reserved

\title{
Association between the irequency of class II HLA antigens and the suscep- tibility to intrauterine infection of hepatitis B virus
}

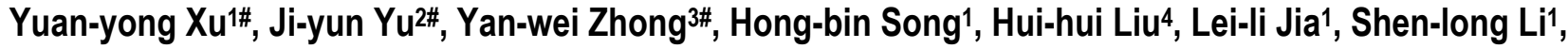 \\ Jian-qiu XuF ${ }^{5}$, Qiao $\mathrm{Li}^{2}, 6$
}

1. Institute of Disease Control and Prevention, Academy of Military Medical Science, Beijing, China

2. Institue of Basic Medical Sciences, Beijing, China.

3. 302 Hospital of PLA, Beijing, China.

4. Department of Epidemiology, Chinese Center for Disease Control and Prevention, Beijing, China.

5. Department of Obstetrics and Gynecology, Maternal and Child Health Hospital of Shaanxi Province, Xi'an, Shaanxi, China.

6. Department of Surgery, University of Michigan, Ann Arbor, Michigan, USA

\#These authors contributed equally to the work

Correspondence to: Hong-bin Song or Qiao Li, Institute of Disease Control and Prevention, Academy of Military Medical Science, 100071, Beijing, China. Phone/Fax:+86-010-66933358.Email:hongbinsong@263.net; or Department of Surgery, University of Michigan, Ann Arbor, MI 48109, USA. Phone: 734-615-1977, Fax: 734-763-4135: Email: qiaoli@umich.edu

Received: 2008.03.24; Accepted: 2008.04.24; Published: 2008.04.25

Multiple factors determine the susceptibility to intrauterine hepatitis B virus (HBV) infection. These factors include the HBV structure, HBV mutation, HBV DNA level, placental barrier, the immune status of the mother, and the genetic make-ups of the newborn infants. Since HLA system is an integral component of the immune response, we hypothesized that the highly polymorphic HLA genes are the key determinants of intrauterine HBV infection. In this study, we selected newborn infants of HBsAg-positive mothers, and divided the infants into 2 groups: intrauterine infection group and non-intrauterine infection group according to the status whether or not they were infected at birth. Each infected infant was compared with 2 controls from the same birth cohort. HLA-DR allele typing was performed using a PCR-sequence specific primer (PCR-SSP) for 24 subjects with intrauterine infection and 48 controls without infection. We found that, among the fifteen (15) HLA-DR alleles assessed, HLA-DRB1*07 was the one, and the only one, significantly in excess $(\mathrm{OR}=6.66, P=0.004)$ in the intrauterine infection group compared to the non-intrauterine infection group. Our findings thus suggest that high frequency of HLA class II molecules, e.g. HLA-DRB1*07, is associated with the susceptibility of the infants to intrauterine HBV infection.

Key words: Hepatitis B virus (HBV); Human leukocyte antigen (HLA); Genetic susceptibility; Intrauterine infection; Nested case-control study

\section{Introduction}

Hepatitis B is a common disease worldwide. Approximately, one million human deaths in the world each year are attributable to the end stage sequelae of persistent hepatitis B virus (HBV) infection. The World Health Organization (WHO) has estimated that about 350 million people worldwide are chronically infected with HBV [1]. These individuals are prone to the development of chronic hepatitis, liver cirrhosis, and hepatocellular carcinoma. In South East Asia, the mode of HBV infection is mainly vertical transmission in the perinatal period. In China, one of the major reasons for the high prevalence of HBV infection is that mothers transmit the HBV to their children during the intrauterine as well as perinatal periods. Approximately $50 \% \mathrm{HBV}$ carriers got infected via mother-to-infant transmission [1, 2, 3]. With the immunolization of hepatitis $B$ vaccine and the use of hepatitis B immunoglobulin (HBIG) in hepatitis B surface antigen (HBsAg)-positive pregnant women, the incidence of HBV carrier status among the children has reduced dramatically. However, intrauterine HBV infection still occurs at high incidence. The exact mechanisms underlying intrauterine infection of HBV have not been completely elucidated. Previous studies showed that major histocompatibility complex (MHC) gene products were vital for the regulation of several antiviral immune reactions [4,5]. In addition, genetic factors controlling the host immune response could play an important role in determining the infection outcome [6,7]. These immune responses may be genetically determined, since studies on twins and families have suggested the contribution of an inherited 
component in the development of chronic hepatitis B infection [8].

$\mathrm{T}$ cell responses are restricted by human leukocyte antigen (HLA) class I and class II molecules, which present antigens to CD8+ cytolytic T cells and CD4+ helper T cells, respectively. The genes encoding HLA class I and class II molecules are the most polymorphic genes in the human genome and are therefore ideal candidates for the investigation of HBV infection susceptibility.

The association between HLA polymorphism and disease susceptibility as well as disease resistance has been documented [9, 10, 11]. Recently, several non-genetic diseases were found to be related to gene polymorphism, and the relationship between the TNF- $\alpha-238 \mathrm{~A}$ and IFN- $\gamma+874 \mathrm{~A}$ alleles and intrauterine HBV infection was reported $[12,13]$. It is important to further examine the relationship between intrauterine HBV infection and HLA gene polymorphism.

To study the association between the polymorphisms of HLA class II genes and intrauterine HBV infection, we selected the newborn infants delivered by HBsAg-positive mothers in this study and compared the frequencies of HLA phenotypes between the intrauterine $\mathrm{HBV}$ infection infant group and the non-intrauterine HBV infection infant group. To this end, an 1:2 matched nested case-control design was used.

\section{Materials and Methods \\ Patients}

This study included the patients who visited the Department of Obstetrics and Gynecology at the Maternity and Child Care Centre of ShanXi Province from February 1999 to October 2004. A written consent was obtained from each of the participants. A nested case-control design was used. The patients selected were newborn infants whose blood were tested positive for $\mathrm{HBsAg}$ within $24 \mathrm{hr}$ of birth (intrauterine HBV infection group, $\mathrm{N}=24$ ). The controls were newborn infants whose blood were tested negative for HBsAg (non-intrauterine HBV infection group, $\mathrm{N}=$ 48). Each patient was compared with 2 controls from the same cohort based on factors that were associated with the pregnant women as well as the newborn infants. These factors included age of the newborns (difference was within 6 months); same gender of the newborns, and the HBV marker levels in the maternal serum before delivery.

\section{Specimen Collection}

Venous blood specimens from pregnant women and femoral vein blood specimens of the newborn infants were collected within $24 \mathrm{hr}$ after birth and stored at $-20^{\circ} \mathrm{C}$ for laboratory testing. After blood collection, the newborn infants immediately received hepatitis B immune globulin (HBIG) intramuscularly. They were also administered with hepatitis $B$ vaccines at month 0,1 , and 6 .

\section{Criteria for Intrauterine HBV Infection}

Newborn infants whose venous blood specimens were collected within $24 \mathrm{hr}$ after birth, if found positive for HBsAg and/or HBV DNA, were considered $\mathrm{HBV}$ infected intrauterinely. In order to exclude the possibility that the intrauterine infection was tested positive due to transplacental maternal contamination of the fetal circulation, we followed up all of the patients for at least 6 months.

\section{Determination of HBsAg and HBeAg in Serum}

The presence of serum HBsAg and HBeAg was tested by ELISA (Shanghai Ke-hua Biotechnology Company, Shanghai, China). The results were generated using a Multiskan MK3 ELISA detector. A positive/negative $(\mathrm{P} / \mathrm{N})$ ratio $\geq 2.1$ was considered positive.

\section{Extraction of Genomic DNA}

The genomic DNA of the newborns was extracted from peripheral blood mononuclear cells by using the QIAamp blood kit (QIAGEN Inc., Chatsworth, CA) according to the manufacturer's instructions.

\section{HLA class II Typing}

HLA class II alleles were typed using the low-resolution DNA typing method--a polymerase chain reaction-sequence specific primer (PCR-SSP) technique (Pel-Freez, Brown Deer, WI) according to the manufacturer's instructions. Gene typing was performed using the software supplied by the company.

\section{Statistical analysis}

Statistical analysis was performed using the SPSS11.0 package software (SPSS Inc., Chicago, IL) on a computer. The frequency of HLA class II alleles was calculated by direct counting. Odds ratios (OR) reflect the likelihood of a specific allele being present in a subject who has intrauterine infection. $P$ values were calculated by using conditional logistic regression. Statistic significance was tested by the chi-square test and Fisher's exact test. $P<0.05$ was considered statistically significant.

\section{Results}

\section{Patient characteristics}

A total of $312 \mathrm{HBsAg}$-positive pregnant women delivered 313 newborn infants from February 1999 to October 2004 in the Department of Obstetrics and Gynecology at the Maternity and Child Care Centre of 
ShanXi Province. There were twins among these newborn infants. Among the 313 newborns, a total of 24 fulfilled our criteria for intrauterine HBV infection, and the infection rate was $7.7 \%(24 / 313)$. There was a significant difference in the maternal serum $\mathrm{HBeAg}$ rate $\left(\chi^{2}=19.50, P<0.0001\right)$ and the newborn serum HBeAg rate $\left(\chi^{2}=17.62, P<0.0001\right)$ between the intrauterine HBV infection and non-intrauterine HBV infection groups. These results indicate that maternal HBeAg-positive serum was a risk factor for intrauterine HBV infection, and the OR was 5.95 (Table 1). In addition, newborn HBeAg-positive serum was also a risk factor with an OR of 5.39 (Table 1).

Table 1 Relationship of serum HBeAg in mothers and newborns to intrauterine infection

\begin{tabular}{|c|c|c|c|c|c|c|}
\hline \multirow[t]{2}{*}{ Group } & \multicolumn{3}{|c|}{ Maternal HBeAg } & \multicolumn{3}{|c|}{ Newborn infants HBeAg } \\
\hline & $\begin{array}{c}\text { Positive } \\
(\%)\end{array}$ & $\begin{array}{c}\text { Negative } \\
(\%)\end{array}$ & $\begin{array}{c}\text { Total } \\
\text { (n) }\end{array}$ & $\begin{array}{c}\text { Positive } \\
(\%)\end{array}$ & $\begin{array}{c}\text { Negative } \\
(\%)\end{array}$ & $\begin{array}{c}\text { Total } \\
\text { (n) }\end{array}$ \\
\hline $\begin{array}{c}\text { Intrauterine } \\
\text { infection }\end{array}$ & $15(62.5 \%)$ & $9(37.5 \%)$ & 24 & $13(54.2 \%)$ & $11(45.8 \%)$ & 24 \\
\hline $\begin{array}{l}\text { Non-intrau- } \\
\text { terine in- } \\
\text { fection }\end{array}$ & $63(21.9 \%)$ & $225(78.1 \%)$ & 288 & $52(18.0 \%)$ & $237(82.0 \%)$ & 289 \\
\hline Total & $78(24.3 \%)$ & $234(75.7 \%)$ & 312 & $65(20.8 \%)$ & $248(79.2 \%)$ & 313 \\
\hline$\chi^{2}$ & & $19.50^{*}$ & & & $17.62^{*}$ & \\
\hline OR $(95 \% \mathrm{CI})$ & 5.95 & $5(2.29-16.8)$ & & 5.39 & $(2.08-13.99)$ & \\
\hline
\end{tabular}

${ }^{*} P<0.0001$

There was no statistically significant difference $(P$ $>0.05$ ) between the infected infants and controls with respect to the mean age and occupation of the mothers, nor the birth weight and gender of the newborn infants.

\section{Distribution of HLA-DR type in the intrauterine infection and non-intrauterine infection groups}

In all the newborn infants, DRB3* was the most frequent HLA-DR type. Its frequency was $37.5 \%$ in the intrauterine infection group and $29.17 \%$ in the non-intrauterine infection group (Table 2). In the intrauterine infection group, DRB1*07 and DRB3* were the most frequent HLA-DR type (both were $37.5 \%$ ) in newborn infants, followed by DRB1*08 $(20.83 \%)$. In the non-intrauterine infection group, $\mathrm{DRB}^{*}$ was the most frequent HLA-DR type $(29.17 \%)$, followed by DRB1*12 (18.75\%) (Table 2).

\section{Comparison of the frequency of the HLA-DR type between the intrauterine infection and non-intrauterine infection groups}

There was a significant difference in the distribution of HLA-DRB1*07 between the intrauterine infection and non-intrauterine infection groups. HLA-DRB1*07 was significantly more frequent in the intrauterine infection group ( 9 of 24 subjects, $37.5 \%$ ) as compared to its frequency in the non-intrauterine infection group (4 of 48 subjects, $8.33 \%$ ) (OR $=6.66, P=$
$0.004)$ (Table 3). The same analysis did not yield evidence supporting the significant $(\mathrm{p}<0.05)$ involvement of other HLA-DR types as determinants of intrauterine infection (Table 3).

Table 2 Frequencies of HLA-DR types in the intrauterine infection and non-intrauterine infection groups\#

\begin{tabular}{|c|c|c|c|c|}
\hline \multirow[t]{2}{*}{$\begin{array}{l}\text { HLA-DR } \\
\text { Allele type }\end{array}$} & \multicolumn{2}{|c|}{$\begin{array}{l}\text { Intrauterine infection } \\
\text { group }(\mathrm{N}=24)\end{array}$} & \multicolumn{2}{|c|}{$\begin{array}{l}\text { Non-intrauterine infection } \\
\text { group } \\
(\mathrm{N}=48)\end{array}$} \\
\hline & $\mathrm{N}$ & $\%$ & $\mathrm{n}$ & $\%$ \\
\hline DRB1*01 & 2 & 8.33 & 2 & 4.17 \\
\hline DRB1*03 & 2 & 8.33 & 5 & 10.42 \\
\hline DRB1*04 & 4 & 16.67 & 3 & 6.25 \\
\hline DRB1*07 & 9 & 37.5 & 4 & 8.33 \\
\hline DRB1*08 & 5 & 20.83 & 5 & 10.42 \\
\hline DRB1*09 & 4 & 16.67 & 4 & 8.33 \\
\hline DRB1*10 & 3 & 12.5 & 2 & 4.17 \\
\hline DRB1*11 & 3 & 12.5 & 7 & 14.58 \\
\hline DRB1*12 & 2 & 8.33 & 9 & 18.75 \\
\hline DRB1*14 & 1 & 4.17 & 7 & 14.58 \\
\hline DRB1*15 & 1 & 4.17 & 8 & 16.67 \\
\hline DRB1*16 & 2 & 8.33 & 3 & 6.25 \\
\hline DRB3* & 9 & 37.5 & 14 & 29.17 \\
\hline DRB4* & 4 & 16.67 & 5 & 10.42 \\
\hline DRB5* & 1 & 4.17 & 3 & 6.25 \\
\hline
\end{tabular}

\#The allele carrier frequencies are referred to the frequencies of the population, not individuals.

Table 3 Comparison of HLA-DR types between the intrauterine infection and non-intrauterine infection groups

\begin{tabular}{|c|c|c|c|c|c|}
\hline \multirow[t]{2}{*}{$\begin{array}{l}\text { HLA-DR } \\
\text { allele }\end{array}$} & \multicolumn{2}{|c|}{$\begin{array}{l}\text { Frequency }(\%) \text { in } \\
\text { Subjects with }\end{array}$} & \multirow[t]{2}{*}{ OR } & \multirow[t]{2}{*}{$95 \% \mathrm{CI}$} & \multirow[t]{2}{*}{$P$} \\
\hline & $\begin{array}{c}\text { Intrauterine } \\
\text { infection } \\
(\mathrm{n}=24)\end{array}$ & $\begin{array}{l}\text { Non-intrauterine } \\
\text { infection }(n=48)\end{array}$ & & & \\
\hline DRB1*01 & 8.33 & 4.17 & 2.091 & $0.276-15.83$ & 0.597 \\
\hline DRB1*03 & 8.33 & 10.42 & 0.782 & $0.14-4.36$ & 0.571 \\
\hline DRB1*04 & 16.67 & 6.25 & 3.00 & $0.61-14.67$ & 0.212 \\
\hline DRB1*07 & 37.5 & 8.33 & 6.66 & $1.77-24.59$ & 0.004 \\
\hline DRB1*08 & 20.83 & 10.42 & 2.26 & $0.58-8.74$ & 0.285 \\
\hline DRB1*09 & 16.67 & 8.33 & 2.2 & $0.49-9.69$ & 0.427 \\
\hline DRB1*10 & 12.5 & 4.17 & 3.28 & $0.51-21.15$ & 0.325 \\
\hline DRB1*11 & 12.5 & 14.58 & 0.83 & $0.19-3.57$ & 0.81 \\
\hline DRB1*12 & 8.33 & 18.75 & 0.39 & $0.08-1.98$ & 0.32 \\
\hline DRB1*14 & 4.17 & 14.58 & 0.25 & $0.29-2.20$ & 0.25 \\
\hline DRB1*15 & 4.17 & 16.67 & 0.21 & $0.03-1.85$ & 0.26 \\
\hline DRB1*16 & 8.33 & 6.25 & 1.36 & $0.21-8.76$ & 1.00 \\
\hline DRB3* & 37.5 & 29.17 & 1.45 & $0.52-4.10$ & 0.59 \\
\hline DRB4* & 16.67 & 10.42 & 1.72 & $0.42-7.10$ & 0.47 \\
\hline DRB5* & 4.17 & 6.25 & 0.65 & $0.06-6.62$ & 1.00 \\
\hline
\end{tabular}

\section{Discussion}

The susceptibility of HBV infection and the immune response to HBsAg-derived vaccines are determined by the genetic background of the host [14, 15]. Other outcomes, including progression to cirrhosis and/or liver cancer, may also be influenced by host genetics. Thus far, the results of studies on host susceptibility to HBV infection are not conclusive. From the viewpoint of epidemiology, the major problem is the lack of appropriate subjects and suitable research 
design. In general, in order to conduct such studies, all subjects should be exposed to HBV. In addition, the time and mode of exposure to HBV should be comparable. Then, the difference in the distribution/frequencies of HLA types can be compared between $\mathrm{HBV}$-infected persons and non-infected controls. Unfortunately, such study designs can hardly be realized if our epidemiological survey is based on the common human population. This is because: (1) It is difficult to determine the precise time of HBV exposure and to conduct follow-ups in common human population; (2) Theoretically, we would first require an isolated population from which our subjects can be selected. From this isolated population, the susceptible population should be screened, and subsequently, the infection status of this population should be followed up. However, this is extremely difficult to achieve. Fortunately, intrauterine HBV infection can be studied in newborn infants who are suitable study subjects. Because the newborn infants we studied were all delivered by HBsAg-positive mothers, they were all susceptible to HBV, and their mothers were the only source of HBV infection. These conditions well satisfies our research design requirements.

HLA is involved in immune response to HBV. Although the relationship between various clinical manifestations and polymorphic HLA genes have been the subject of several studies, a definitive relationship has not yet been identified due to the inconsistencies of the results $[4,16,17,18]$. While the mechanism of susceptibility to HBV infection is not well clarified, it is known to be influenced by host immunogenetic factors $[19,20]$.

Our results show that maternal $\mathrm{HBeAg}$-positive serum and newborn $\mathrm{HBeAg}$-positive serum were risk factors for intrauterine HBV infection. Several reports indicated that the likelihood of developing chronic $\mathrm{HBV}$ infection is higher in newborn infants, whose immune systems are thought to be immature, compared with the immunocompetent subjects during adulthood [14, 23]. The natural course of chronic HBV infection can be divided into four phases based on the virus-host interaction: immune tolerance, immune clearance, low or non-replication, and reactivation. Most carries with intrauterine HBV infection are present in the immunotolerant phase. These carries are HBeAg positive but with normal alanine aminotransferase (ALT).

Our study has indicated that HLA-DRB1*07(HLA-DR7) type is associated with HBV intrauterine infection in Chinese people. It is noticeable that in this study the newborn infants with non-intrauterine HBV infection were selected as the controls, which ensured a similar exposure to $\mathrm{HBV}$ between the case and control groups. Our results imply that susceptibility to persistent infection is significantly associated with the presence of HLA-DR7 type. Almarri et al [21] failed to identify an association between HLA class I and chronic HBV infection. However, they discovered a significant decrease in the frequency of HLA-DR2 and an excess of HLA-DR7 in cases of chronic, persistent HBV infection. HLA-DRB1*1301/2 has been associated with viral clearance, but HLA-DRB1*07(HLA-DR7) is associated with non-responsiveness to vaccination with envelope proteins $[4,22]$. It is possible that high expression of HLA-DR7 on the cell surface may restrict the ability of helper T-lymphocytes to recognize HBsAg and B-cells and thereby result in persistent infection. Alternatively, HLA-DR7 may present viral peptides to a specific subset of CD4+ T cells and therefore alt the subsequent immune responses. Nevertheless, compared with our study, those studies did not show the role of HLA-DRB1*07(HLA-DR7) in HBV intrauterine infection.

To the best of our knowledge, this is the first report involving the study on the association between HLA phenotypes and the outcomes of intrauterine HBV infection in newborn infants. Our data have showed that high frequency of specific HLA phenotypes, such as DRB1*07, is associated with the susceptibility to HBV intrauterine infection. Thus, our findings support the conclusion that genetic factors (e.g., HLA) are associated with the outcomes of intrauterine HBV infection. The characterization of functional significance of this particular HLA molecule in HBV intrauterine infection may provide insight to develop novel prophylactic and therapeutic approaches. Additional study is needed to validate these findings and to further explore the relationship between HBV intrauterine infection and the susceptible gene(s), as well as any other risk factors which may be involved in HBV intrauterine infection. Finally, investigation to elucidate the genetic pathogenesis of HBV intrauterine infection is among the future studies we plan to pursue.

\section{Acknowledgements}

We thank Prof. De-Zhong Xu for his discussion. This work was supported by a grant from the National Natural Science Foundation of China (No. 30230320).

\section{Conflict of interest}

The authors have declared that no conflict of interest exists.

\section{References}

1. Franchis R, Hadengue A, Lau G, et al. Proceedings of the European Association for the Study of the Liver (EASL) International Consensus Conference on Hepatitis B, September 14-16, 2002, Geneva, Switzerland. J Hepatol 2003; 39(Suppl 1):1-235. 
2. Shiraki K. Perinatal transmission of hepatitis B virus and its prevention. J Gastroenterol Hepatol 2000; 15:11-15.

3. Wang JS, Zhu QR. [Interruption of the transmission of hepatitis $\mathrm{B}$ virus from mother to babies]. Zhonghua Gan Zang Bing Za Zhi 2002; 10:308-10.

4. Thio CL, Thomas DL, Karacki P, et al. Comprehensive analysis of class I and class II HLA antigens and chronic hepatitis B virus infection. J Virol. 2003; 77: 12083-7.

5. Pajot A, Pancré V, Fazilleau N, et al. Comparison of HLA-DR1-restricted $\mathrm{T}$ cell response induced in HLA-DR1 transgenic mice deficient for murine MHC class II and HLA-DR1 transgenic mice expressing endogenous murine MHC class II molecules. Int Immunol. 2004; 16:1275-82.

6. Rapicetta M, Ferrari C, Levrero M. Viral determinants and host immune responses in the pathogenesis of HBV infection. J Med Virol. 2002; 67:454-7.

7. Hui CK, Lau GK. Immune system and hepatitis B virus infection. J Clin Virol. 2005; 34: S44-8.

8. Lin TM, Chen CJ, Wu MM, et al. Hepatitis B virus markers in Chinese twins. Anticancer Res 1989; 9:737-41.

9. Wu YF, Wang LY, Lee TD, et al. HLA phenotypes and outcomes of hepatitis B virus infection in Taiwan. J Med Virol 2004;72:17-25.

10. Godkin A, Davenport M, Hill AV. Molecular analysis of HLA class II associations with hepatitis B virus clearance and vaccine nonresponsiveness. Hepatology 2005; 41:1383-90.

11. Han YN, Yang JL, Zheng SG, et al. Relationship of human leukocyte antigen class II genes with the susceptibility to hepatitis B virus infection and the response to interferon in HBV-infected patients. World J Gastroenterol 2005; 11:5721-4.

12. Zhu QR, Ge YL, Gu SQ, et al. Relationship between cytokines gene polymorphism and susceptibility to hepatitis B virus intrauterine infection. Chin Med J (Engl) 2005; 118:1604-9.

13. Gu SQ, Zhu QR, Yu H, et al. Relationship between genetic polymorphism of tumor necrosis factor-alpha and susceptibility to intrauterine HBV infection. Zhonghua Gan Zang Bing Za Zhi 2004; 12:538-9.

14. The EASL Jury. Easl international consensus conference on hepatitis B. J Hepatol 2003; 38:533-40.

15. Shirak K. Perinatal transmission of hepatitis B virus and its prevention. J Gastroenterol Hepatol. 2000;15:E11-E15.

16. Meng $X Q$, Chen HG, Ma YL, et al. Influence of HLA classII molecules on the outcome of hepatitis B virus infection in population of Zhejiang Province in China. Hepatobiliary Pancreat Dis Int. 2003; 2: 230-3.

17. Jiang YG, Wang YM, Liu TH, et al. Association between HLA class II gene and susceptibility or resistance to chronic hepatitis B. World J Gastroenterol. 2003; 9: 2221-5.

18. Ahn SH, Han KH, Park JY, et al. Association between hepatitis B virus infection and HLA-DR type in Korea. Hepatology. 2000; 31: 1371-3.

19. Thursz MR. Host genetic factors influencing the outcome of hepatitis. J Viral Hepat 1997; 4:215-20.

20. Diepolder HM, Jung MC, Keller E, et al. A vigorous virus-specific $\mathrm{CD} 4+\mathrm{T}$ cell response may contribute to the association of HLA-DR13 with viral clearance in hepatitis B. Clin Exp Immunol 1998; 113: 244-51.

21. Almarri A, Batchelor JR. HLA and hepatitis B infection. Lancet. 1994; 344: 1194-5.

22. Kazim SN, Wakil SM, Khan LA, et al. Vertical transmission of hepatitis B virus despite maternal lamivudine therapy. Lancet.2002; 359:1488-9.

23. Giovanna F, Bortolotti F, Francesco D. Natural history of chronic hepatitis B: special emphasis on disease progression and prognostic factors. J Hepatol.2008; 48:335-52. 